\title{
TOPICAL USE OF APROTININ IN CORONARY ARTERY BYPASS SURGERY
}

\author{
Jiři Mand’ák, Vladimír Lonský, Jan Dominik
}

Charles University in Prague, Faculty of Medicine in Hradec Králové: Department of Cardiosurgery

Summary: Objective: The internal mammary artery (IMA) ranks among excellent, widely used conduits for surgical coronary revascularization. Its harvesting and its using may cause other surgical and technical problems and complications and increase postoperative bleeding from wound surface after the IMA harvesting with significantly greater incidence of blood transfusion. The aim of this study was to get to know how much it increases postoperative bleeding losses and if the local application of aprotinin (to the wound surface after the IMA harvesting and into the pericardial cavity) can reduce them and thus decrease the number of blood transfusions. Methods: In this study there are compared groups of patients $(n=275)$ operated at the University Department of Cardiac Surgery in Hradec Králové on account of ischemic heart disease. In the first part of this study results of operations of 200 patients were comprised retrospectively. Group A1 comprised 50 patients where for revascularization of the myocardium venous grafts were used. Group B1 comprised 50 patients where also the internal mammary artery was used. Group $\mathrm{C} 1$ was formed by 50 patients where after preparation of the IMA aprotinin (100 $000 \mathrm{KIU}$ ) was administered locally to the wound surface after the IMA harvesting. Group D1 was formed by 50 patients where aprotinin $(500000 \mathrm{KIU})$ was administered locally to the wound surface and poured into the pericardial cavity before closure of the median sternotomy. The postoperative blood losses and the number of the administered blood transfusions were compared between these groups. Results: The authors provided evidence that the using of the IMA increases significantly the postoperative blood losses (in group A1 $675 \mathrm{ml} \pm 352.9$, in group B1 $1232 \mathrm{ml}$ \pm 336.5 ) and increases the number of required transfusions (in group A1 $2.44 \pm 1.7$, in group B1 $3.45 \pm 1.0$ ). By local aprotinin application to the wound surface after the IMA harvesting the blood losses and the number of administered transfusions were reduced in group $\mathrm{C} 1(896 \mathrm{ml}(231.9,2.74 \pm 0.8)$. In group D1 (local aprotinin application to the wound surface and into the pericardial cavity) the blood losses and the number of transfusions were increasingly reduced than in group $\mathrm{C} 1(797 \mathrm{ml} \pm 280.5,1.74 \pm 1.3)$. In the second, prospective randomised part of this study 3 groups of patients were compared. Group A2 comprised 25 patients where venous grafts for revascularization of myocardium were used. Group B2 was formed by 25 patients where also the IMA was used. Group D2 comprised 25 patients where aprotinin (500 $000 \mathrm{u}$.) was administered locally to the wound surface after the IMA harvesting and poured into the pericardial cavity before closure of sternotomy. The postoperative blood losses and the number of administered blood transfusions were again compared between these groups. The total postoperative blood losses were $778 \mathrm{ml} \pm 304.2$ in group A2, $1072 \mathrm{ml} \pm 391.8 \mathrm{in}$ group B2 and $754 \mathrm{ml} \pm 197.9$ in group D2. There were compared blood losses after 6, 12 and 24 hours, too. There were the statistically significant differences among these groups during the whole postoperative period. The number of blood transfusions were $2.8 \pm 2.3$ in group A2 and $2.04 \pm 1.1$ in group B2. The use of aprotinin decreased this number in group $\mathrm{D} 2,1.44 \pm 1.1$. Conclusions: The authors provided evidence that the harvesting and the using of the internal mammary artery for myocardial revascularization increases significantly the postoperative bleeding and increases the number of required transfusions. By local application of aprotinin the author reduced the blood losses and need of transfusions.

Key words: Open-heart surgery; Ischemic heart disease; Internal mammary artery; Aprotinin; Postoperative bleeding; Blood transfusions

\section{Introduction}

Use of the internal mammary artery (IMA) as a graft for myocardial revascularization ranks among standard, widely used methods in cardiac surgery. It was based on the excellent long term results of patency when compared with venous conduits $(2,12)$.

Surgical techniques for harvesting of the IMA are well known. But its harvesting and its using may cause other sur- gical and technical problems and complications such as a prolonged operative time, spasm of the IMA, poor artery blood flow, pneumothorax, chylothorax, brachial plexus lesion, phrenic nerve injury, steal syndrom, sternal fracture, sternal wound infection and increased bleeding from wound surface after the IMA harvesting $(1,2,4,5,11,12,17)$.

Bleeding after open - heart surgery is still one of the major problems. The effect of cardiopulmonary bypass (CPB) is well-known and discussed in many papers $(9,14,18)$. 
Blood losses can lead to other complications and require blood transfusion. It carries a risk of infectious disease, adverse reactions and increases a total price of the operation and the postoperative care $(8,18)$.

Therefore, many ways have been explored to reduce perand postoperative bleeding and the need for homologous blood transfusion, such as intraoperative transfusion, hemodilution, postoperative return of shed mediastinal blood and the use of farmacological agents $(6,7,18)$.

Aprotinin, the serum protease inhibitor, has been shown to be effective in reducing postoperative blood loss in patients undergoing CPB. Its effect on coagulation cascade, clotting, fibrinolysis and complement system has been investigated by many researches and its clinical effectiveness has been documented $(3,6,15)$. The haemostatic effect of aprotinin resulting in reduction of homologous blood transfusion is unquestionable, too. Aprotinin is administrated before and during CPB intravenously or into the prime of the oxygenator $(3,15)$.

Topical use of aprotinin is neither common nor widespread in cardiac surgery. The application of 500000 $1000000 \mathrm{KIU}$ into the pericardial cavity before closure of the median sternotomy has been presented in few papers $(13,16)$.

Local application of aprotinin to the wound surface after the IMA harvesting and into the pericardial cavity is presented in this study. Fig. 1,2.

The aim of this study was to get to know how much the harvesting and the using of the IMA for revascularization of myocardium increases postoperative blood losses. The second aim was to obtain an answer if the local application of aprotinin can reduce them and thus decrease the number of blood tranfusions.

\section{Material and methods}

In this study there are compared groups of patients ( $\mathrm{n}=$ 275) operated at the University Department of Cardiac

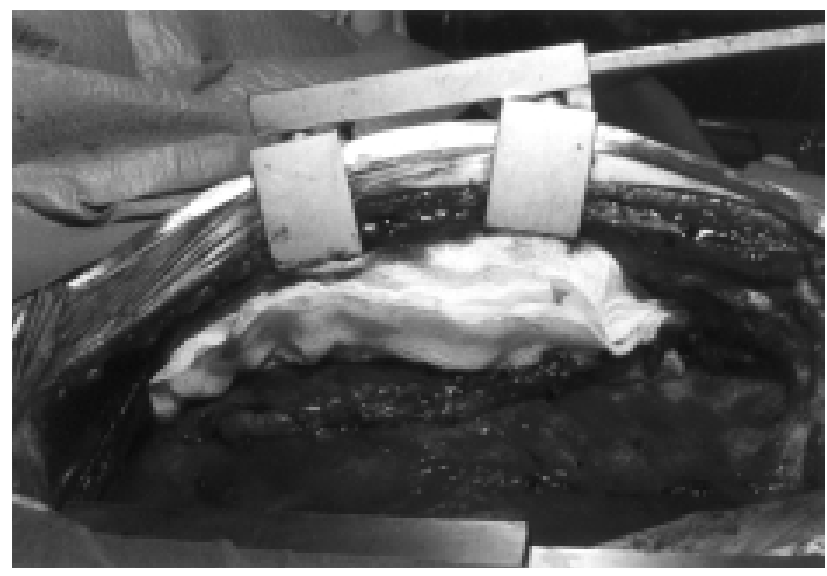

Fig. 1: Local application of aprotinin to the wound surface after the IMA harvesting.
Surgery in Hradec Králové, Czech Republic, on account of ischemic heart disease.

In the first part of this study results of the operations on 200 patients were comprised retrospectively. Group A1 comprised 50 patients where for revascularization of the myocardium venous grafts were used. Group B1 comprised 50 patients where also internal mammary artery was used. Group C1 was formed by 50 patients where after preparation of the IMA aprotinin ( $100000 \mathrm{KIU})$ was administered locally to the wound surface after the IMA harvesting. Fig 1,2. Group D1 was formed by 50 patients where aprotinin (500 $000 \mathrm{KIU}$ ) was administered locally to the wound surface after harvesting of the IMA and poured into the pericardial cavity before closure of the median sternotomy. Fig. 1,2. The postoperative blood losses from mediastinal, pericardial and pleural drains and the number of the administered blood transfusions were compared between these groups.

In the second, prospective randomised part of this study 3 groups of patients were compared.Group A2 comprised 25 patients where for revascularization of myocardium only venous grafts were used. Group B2 was formed by 25 patients where also the IMA was used. Group D2 comprised 25 patients where aprotinin (500 $000 \mathrm{KIU})$ was administered locally to the wound surface after the IMA harvesting and poured into the pericardial cavity before closure of sternotomy. The postoperative blood losses and the number of administered blood transfusions were compared in these groups again. It was shown in the first part of this study that local application of aprotinin (500 $000 \mathrm{u}$.) to the wound surface and to the pericardial cavity (D1) can reduce blood losses more than the application (100 $000 \mathrm{u}$.) to the wound surface only $(\mathrm{C} 1)$. That's why no Group $\mathrm{C} 2$ was compared in the second part of the study.

The anesthesia management, CPB and surgical procedures were standardized. Anesthesia was induced with fentanyl and flunitrazepam, muscle relaxation with pipecuronium bromide. The extracorporeal circuit consisted of membrane oxygenators and roller pumps. Oxygenators and

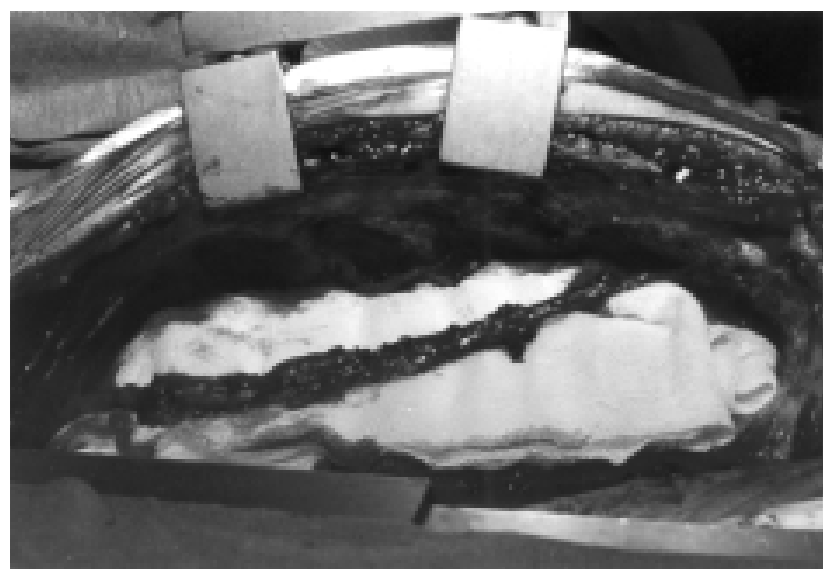

Fig. 2: Local application of aprotinin to the wound surface after the IMA harvesting. 
tubing were primed with Hartmann's solution, low molecular weight dextran, $10 \%$ mannitol solution, gelatin solution, $8.4 \%$ sodium bicarbonate, magnesium sulphate, methylprednisolone, heparin $2500 \mathrm{u}$. and aprotinin $500000 \mathrm{KIU}$. Patients were heparinized before CPB with $2.5 \mathrm{mg} / \mathrm{kg}$ heparin. Additional doses of heparin were given when ACT was shorter than 400 seconds. After CPB, heparin was neutralized with protamin at a 1:1 ratio. A standard aortic and a two-stage venous cannula were used. Moderate hypotermia $\left(28-30^{\circ} \mathrm{C}\right)$, cold crystalloid potassium cardioplegia (St. Thomas Hospital Solution) and topical cooling were employed for myocardial protection. Saphenous vein and left internal mammary artery were used for revascularization of myocardium. Pericardial cavity, mediastinal and pleural spaces were drained after operations. The amount of blood losses was measured every hour in postoperative time. The drains were removed after 48 hours. Shed mediastinal blood was not transfused in any patient. Blood transfusions were administered only when the hematocrit value fell to less than 0.25 and hemoglobin less than 95. Autotransfusions were not included. There were 9 reoperations for bleeding in this study. Blood losses of these were included.

Patients in which both mammary arteries were used and patients undergoing REDO surgery were not admitted to the study. Preoperative blood tests were normal in all patients.

Student's t- test was used for statistical analysis. A p value less than 0.05 was considered statistically significant.

Aprotinin (Antilysin Spofa, Gordox Gedeon Richter) for topical application was used in doses of 100000 or 500000 KIU.

All operations were done by the same surgeon.

\section{Results}

Peroperative and postoperative data:

Tab. 1: Comparison of Group A1 (venous grafts) and Group B1 (venous grafts + IMA).

\begin{tabular}{|l|c|c|c|}
\hline & $\begin{array}{c}\text { Group A1 } \\
\mathrm{n}=50 \\
(39 \mathrm{~m}, 11 \mathrm{f})\end{array}$ & $\begin{array}{c}\text { Group B1 } \\
\mathrm{n}=50 \\
(46 \mathrm{~m}, 4 \mathrm{f})\end{array}$ & $\mathrm{p}$ \\
\hline age (yrs) & $62.3 \pm 7.6$ & $64.5 \pm 11.5$ & $\mathrm{NS}$ \\
\hline No. of dist. anasomoses & $2.78 \pm 0.7$ & $2.1 \pm 0.9$ & $<0.001$ \\
\hline cross-clamp time (min) & $46.6 \pm 13.0$ & $46.5 \pm 15.0$ & $\mathrm{NS}$ \\
\hline CPB time (min) & $89.9 \pm 21.8$ & $80.5 \pm 27.5$ & $\mathrm{NS}$ \\
\hline total blood losses (ml) & $675 \pm 352.9$ & $1232 \pm 336.5$ & $<0.0001$ \\
\hline blood transfusions (units) & $2.44 \pm 1.7$ & $3.45 \pm 1.0$ & $<0.002$ \\
\hline
\end{tabular}

When comparing the groups A1 and B1 a statistically significant increase of blood losses was found in group B1 where also the mammary artery was used $-1232 \mathrm{ml} \pm 336.5$, when compared with $675 \mathrm{ml} \pm 352.9$ in group A1 where only venous grafts were used. Statistically similarly singificant difference was discovered in numbers of blood units administered in group B1 $(3.45 \pm 1.0)$, while in the group A1 there were $2.44 \pm 1.7$.
Tab. 2: Comparison of Group B1 (venous grafts + IMA) and Group C1 (venous grafts + IMA + aprotinin $100000 \mathrm{KIU})$.

\begin{tabular}{|l|c|c|c|}
\hline & $\begin{array}{c}\text { Group B1 } \\
\mathrm{n}=50 \\
(46 \mathrm{~m}, 4 \mathrm{f})\end{array}$ & $\begin{array}{c}\text { Group C1 } \\
\mathrm{n}=50 \\
(45 \mathrm{~m}, 5 \mathrm{f})\end{array}$ & $\mathrm{p}$ \\
\hline age (yrs) & $64.5 \pm 11.5$ & $54.7 \pm 7.0$ & $<0.001$ \\
\hline No.of dist. anastomoses & $2.1 \pm 0.9$ & $2.8 \pm 0.8$ & $<0.001$ \\
\hline cross-clamp time (min) & $46.5 \pm 15.0$ & $54.3 \pm 19.3$ & $<0.05$ \\
\hline CPB time (min) & $80.5 \pm 27.5$ & $97.1 \pm 29.9$ & $<0.01$ \\
\hline total blood losses (ml) & $1232 \pm 336.5$ & $896 \pm 231.9$ & $<0.001$ \\
\hline blood transfusions (units) & $3.45 \pm 1.0$ & $2.74 \pm 0.8$ & $<0.001$ \\
\hline
\end{tabular}

Comparing groups $\mathrm{C} 1$, where aprotinin $100000 \mathrm{u}$. was used locally, with the group B1, where no aprotinin was used, we witnessed a marked decrease of blood losses (896 $\mathrm{ml}(231.9$ vs. $1232 \mathrm{ml} \pm 336.5)$. Similarly also the statistically significant decrease of blood transfusions was apparent $(2.74 \pm 0.8$ vs. $3.45 \pm 1.0$ units $)$.

Tab. 3: Comparison of Group C1 (venous grafts + IMA + aprotinin $100000 \mathrm{KUI}$ ) and Group D1 (venous grafts 1 IMA + aprotinin $500000 \mathrm{KIU})$.

\begin{tabular}{|l|c|c|c|}
\hline & $\begin{array}{c}\text { Group C1 } \\
\mathrm{n}=50 \\
(45 \mathrm{~m}, 5 \mathrm{f})\end{array}$ & $\begin{array}{c}\text { Group D1 } \\
\mathrm{n}=50 \\
(46 \mathrm{~m}, 4 \mathrm{f})\end{array}$ & $\mathrm{p}$ \\
\hline age (yrs) & $54.7 \pm 7.0$ & $56.2 \pm 8.1$ & $\mathrm{NS}$ \\
\hline No. of dist. anastomoses & $2.8 \pm 0.8$ & $2.7 \pm 0.9$ & $\mathrm{NS}$ \\
\hline cross-clamp time (min) & $54.3 \pm 19.3$ & $44.1 \pm 14.5$ & $<0.001$ \\
\hline CPB time (min) & $97.1 \pm 29.9$ & $84.2 \pm 26.9$ & $<0.05$ \\
\hline total blood losses (ml) & $896 \pm 231.9$ & $797 \pm 280.5$ & $\mathrm{NS}$ \\
\hline blood transfusions (units) & $2.74 \pm 0.8$ & $1.74 \pm 1.3$ & $<0.001$ \\
\hline
\end{tabular}

Though the decrease of blood losses in group D1 could be traced when compared with the group $\mathrm{C} 1$, this was not of a statistical significance. The number of transfusions was increasingly reduced in group D1 than in group C1.

Tab. 4: Comparison of Group B1 (venous grafts 1 IMA) and D1 (venous grafts + IMA + aprotinin $500000 \mathrm{KIU}$ ).

\begin{tabular}{|l|c|c|c|}
\hline & $\begin{array}{c}\text { Group B1 } \\
\mathrm{n}=50 \\
(46 \mathrm{~m}, 4 \mathrm{f})\end{array}$ & $\begin{array}{c}\text { Group D1 } \\
\mathrm{n}=50 \\
(46 \mathrm{~m}, 4 \mathrm{f})\end{array}$ & $\mathrm{p}$ \\
\hline age (yrs) & $64.5 \pm 11.5$ & $56.2 \pm 8.1$ & $<0.001$ \\
\hline No.of dist. anastomoses & $2.1 \pm 0.9$ & $2.7 \pm 0.9$ & $<0.001$ \\
\hline cross-clamp time (min) & $46.5 \pm 15.0$ & $44.1 \pm 14.5$ & $\mathrm{NS}$ \\
\hline CPB time (min) & $80.5 \pm 27.5$ & $84.2 \pm 26.9$ & $\mathrm{NS}$ \\
\hline total blood losses (ml) & $1232 \pm 336.5$ & $797.0 \pm 280.5$ & $<0.001$ \\
\hline blood transfusions (units) & $3.45 \pm 1.0$ & $1.74 \pm 1.3$ & $<0.001$ \\
\hline
\end{tabular}

When paralleling groups B1 and D1 in the third part of our study a statistically significant decrease of blood losses was found in group D1 where $500000 \mathrm{u}$. of aprotinin were used. The average volume here was $797.0 \mathrm{ml} \pm 280.5$, compared with that in the group B1 where it was $1232 \mathrm{ml} \pm 336.5$. Also the statistically significant reduction in units of blood given was found; $3.45 \pm 1.0$ in group B1 and $1.74 \pm 1.3$ in group D1. 
Other parameteres followed in individual groups (age, sex, time of extracorporal circulation, crossclamp time, number of peripheral coronary anastomoses) showed no significant differences at all. Tabs. 1 to 4 .

Tab. 5: Comparison of the main parameters.

\begin{tabular}{|l|c|c|c|c|}
\hline Group & A1 & B1 & C1 & D1 \\
\hline $\begin{array}{l}\text { blood } \\
\text { losses (ml) }\end{array}$ & $675 \pm 352.9$ & $1232 \pm 336.5$ & $896 \pm 231.9$ & $797 \pm 280.5$ \\
\hline $\begin{array}{l}\text { blood } \\
\text { transfusions } \\
\text { (units) }\end{array}$ & $2.44 \pm 1.7$ & $3.45 \pm 1.0$ & $2.74 \pm 0.8$ & $1.74 \pm 1.3$ \\
\hline
\end{tabular}

The general assessment of the main parameters observed in individual groups is being illustrated in Tab 5 .

Tab. 6: Comparison of Group A2 (venous grafts) and Group B2 (venous grafts + IMA).

\begin{tabular}{|l|c|c|c|}
\hline & $\begin{array}{c}\text { Group A2 } \\
\mathrm{n}=25 \\
(19 \mathrm{~m}, 6 \mathrm{f})\end{array}$ & $\begin{array}{c}\text { Group B2 } \\
\mathrm{n}=25 \\
(24 \mathrm{~m}, 1 \mathrm{f})\end{array}$ & $\mathrm{p}$ \\
\hline age (yrs) & $64 \pm 7.9$ & $57.0 \pm 6.8$ & $<0.001$ \\
\hline No. of dist. anastomoses & $2.7 \pm 0.8$ & $2.96 \pm 0.8$ & $\mathrm{NS}$ \\
\hline cross-clamp time (min) & $44.6 \pm 20.4$ & $47.1 \pm 12.2$ & $\mathrm{NS}$ \\
\hline CPB time (min) & $92.7 \pm 30.2$ & $92.6 \pm 34.4$ & $\mathrm{NS}$ \\
\hline 6 hours blood losses (ml) & $280 \pm 160.7$ & $472 \pm 281.4$ & $<0.005$ \\
\hline 12 hours blood losses (ml) & $416 \pm 227.6$ & $610 \pm 305.5$ & $<0.01$ \\
\hline 24 hours blood losses (ml) & $590 \pm 257.4$ & $836 \pm 334.3$ & $<0.005$ \\
\hline pleural blood losses (ml) & $188 \pm 183.6$ & $335 \pm 213.4$ & $<0.05$ \\
\hline total blood losses (ml) & $778 \pm 304.2$ & $1072 \pm 391.8$ & $<0.005$ \\
\hline blood transfusions (units) & $2.8 \pm 2.3$ & $2.04 \pm 1.1$ & $\mathrm{NS}$ \\
\hline
\end{tabular}

When compared the phenomenons followed in groups A 2 and B2 in the second part of this study a statistically significant increase of blood losses in group B2, where mammary artery was used for revascularization, was found (1072 $\mathrm{ml} \pm 391.8)$, when compared with group A2, where this artery was not used $(778 \mathrm{ml} \pm 304.2)$. Higher losses from drains were present within the whole postoperative period. Decrease of blood transfusions was not significant.

Tab. 7: Comparison of Group B2 (venous grafts + IMA) and Group D2 (venous grafts + IMA + aprotinin 500000 KIU).

\begin{tabular}{|l|c|c|c|}
\hline & $\begin{array}{c}\text { Group B2 } \\
\mathrm{n}=25 \\
(24 \mathrm{~m}, 1 \mathrm{f})\end{array}$ & $\begin{array}{c}\text { Group D2 } \\
\mathrm{n}=25 \\
(23 \mathrm{~m}, 2 \mathrm{f})\end{array}$ & $\mathrm{p}$ \\
\hline age (yrs) & $57.0 \pm 6.8$ & $56.0 \pm 7.26$ & $\mathrm{NS}$ \\
No. of dist. anastomoses & $2.96 \pm 0.8$ & $2.64 \pm 0.8$ & $\mathrm{NS}$ \\
cross-clamp time (min) & $47.1 \pm 12.2$ & $43.36 \pm 12.9$ & $\mathrm{NS}$ \\
CPB time (min) & $92.6 \pm 34.4$ & $84.3 \pm 26.4$ & $\mathrm{NS}$ \\
6 hours blood losses (ml) & $472 \pm 281.4$ & $270 \pm 119.9$ & $<0.002$ \\
12 hours blood losses (ml) & $610 \pm 305.5$ & $358 \pm 130.5$ & $<0.001$ \\
24 hours blood losses (ml) & $836 \pm 334.3$ & $568 \pm 174.0$ & $<0.001$ \\
pleural blood losses (ml) & $335 \pm 213.4$ & $92.1 \pm 107.9$ & $<0.01$ \\
total blood losses (ml) & $1072 \pm 391.8$ & $754 \pm 197.9$ & $<0.001$ \\
blood transfusions (units) & $2.04 \pm 1.1$ & $1.44 \pm 1.1$ & $<0.05$ \\
\hline
\end{tabular}

Comparing the groups B2 and D2 we found statistically significant decrease of blood losses within all the investigation time span in group D2, where $500000 \mathrm{u}$. of aprotinin was given (from $1072 \mathrm{ml} \pm 391.8$ in group B2 to $778 \mathrm{ml} \pm$ 304.2 in group D2). Similarly even the number of blood transfusions was lower $(1.44 \pm 1.1$ in group D2 vs. $2.04 \pm$ 1.1 in group B2).

Other investigated parameters in individual groups (age, sex, time of extracorporal circulation, crossclamp time, number of peripheral coronary anastomoses) did not show any significant differences. Tabs. 5 to 6 .

Tab. 8: Comparison of the main parameters.

\begin{tabular}{|l|c|c|c|}
\hline Group & A2 & B2 & D2 \\
\hline $\begin{array}{l}\text { 6 hours blood } \\
\text { losses (ml) }\end{array}$ & $280 \pm 160.7$ & $472 \pm 281.4$ & $270 \pm 119.9$ \\
\hline $\begin{array}{l}\text { 12 hours blood } \\
\text { losses (ml) }\end{array}$ & $416 \pm 227.6$ & $610 \pm 305.5$ & $358 \pm 130.5$ \\
\hline $\begin{array}{l}24 \text { hours blood } \\
\text { losses (ml) }\end{array}$ & $590 \pm 257.4$ & $836 \pm 334.3$ & $568 \pm 174.0$ \\
\hline $\begin{array}{l}\text { pleural blood } \\
\text { losses (ml) }\end{array}$ & $188 \pm 183.6$ & $335 \pm 213.4$ & $192 \pm 107.9$ \\
\hline $\begin{array}{l}\text { total blood } \\
\text { losses (ml) }\end{array}$ & $778 \pm 304.2$ & $1072 \pm 391.8$ & $754 \pm 197.9$ \\
\hline $\begin{array}{l}\text { blood transfu- } \\
\text { sions (units) }\end{array}$ & $2.8 \pm 2.3$ & $2.04 \pm 1.1$ & $1.44 \pm 1.1$ \\
\hline
\end{tabular}

The general assessment of the main parameters observed in individual groups is being illustrated in Tabs. 7 and 8 .

During our study we haven't noted any negative reaction after the local administration of aprotinin.

\section{Discussion}

In cardiac surgery and, above all, in operations with cardiopulmonary bypass (CPB), there are always some blood losses. The amount of blood lost depends on the type of operation performed and on the techniques used. The blood loss prevention seems to represent an important element in the operation treatment. A certain part in this prevention is taken by new techniques of operating and new materials used during both the operation and the CPB, as well as some drugs application for the blood elements protection or hemostasis activation $(5,6,10)$.

Another important factor is represented by the drainage. Individual departments, as well as the authors of published papers, differ when drainage introduction is concerned. Some of them prefer draining the pericardial sac, together with the retrocardial space, by several (2-4) Redon's drains, and besides that they also add the anterior mediastinal drainage $(1,6,12)$. Some others use thick drains introduced into the anterior mediastinum beyond sternum only $(2,13)$.

Similar differences may be found even when concerning the drainage of the pleural cavity when opened during the operation. Some authors do not use any drains $(1,6,14)$, others make use of Redon's drains (2) or of typical chest drains with permanent suction $(9,12)$. Amounts of blood 
losses are thus rather different, since the following punctions or pleural cavity drainages during the postoperative period are not being usually included into the total losses.

Even the drainage time intervals also differ - usually from 24 to 48 hours postoperatively.

No less important fact, which must be set in connection with average blood losses after the heart operations, is the time span when the losses were followed and counted. Some authors take for so called surgical bleeding only the bleeding within the period of 6 hours after the operation (2). Some others suggest $12(6,13)$ or even 24 hours $(15,18)$. The rest of authors check all the blood losses till the drains removal $(9,10)$ or total blood losses, where even the perioperative bleeding is being included (10). That is also why in different papers stated amounts of blood lost largely differ - starting from $286 \mathrm{ml}$ to $1640 \mathrm{ml}$, and in cases of using the previous antiaggregation treatment even to $2070 \mathrm{ml}$ or $2765 \mathrm{ml}$, when counted together with the perioperative losses $(6,7,10)$.

The fact is that blood losses during the first postoperative hours gradually change into fluid losses. The hematocrit and hemoglobin values permanently fall and get bellow the blood values. The blood count of fluid drained from the cavities shows still higher and higher dilution within the period of time, hemoglobin thus reaching values of $74 \ldots 35 \ldots 10$ $\mathrm{g} / 1$ and hematocrit levels $0.22 \ldots 0.12 \ldots 0.08$. That is why we should rather talk about fluid losses than about blood losses.

The sufficient drainage of operation field is of a paramount importance not only because of checking the postoperative bleeding but also because of prevention of some other complications. Above all, the hemopericardium and late inflammatory complications ought to be mentioned.

Equally suitable is also the pleural cavity drainage, if this had been opened during the operation. The amount of losses in these cases is of a high degree of importance, as confirmed by this paper of ours. The losses are being further increased when mammary artery is being harvested and used for myocardial revascularization. Early drainage usually prevents the postoperative punctions and drainage later.

In our study the losses from the chest drain reached on the average $188 \mathrm{ml}$ (A2), $335 \mathrm{ml}$ (B2) and $193 \mathrm{ml}$ (D2). At the first sight such a bleeding does not seem to be too alarming. But the fact of different volumes in different patients is. In some cases of ours the chest tube losses reached as much as $700 \mathrm{ml}$. Moreover, there exists no exact peroperative prediction of postoperative blood losses.

The blood volume lost is being influenced not only by the type of operation but also by some drugs administered. Higher losses can then be seen in urgent and emergency operations, where there was not possible to eliminate in advance the effect of antiaggregants or anticoagulants (10).

Most probably the only objective importance criterion of the peroperative and postoperative blood losses, if drained properly of course, is represented by their influence on the postoperative course, and, above all, on the blood count fall and general hypovolemia. Transfusion and infusion therapy in the postoperative period increases both the possibility of complications risk and nursing and economical requirements of the whole treatment.

By the results of this study we succeeded to confirm that harvesting and using the mammary artery for the myocardial revascularization markedly increases the postoperative blood losses. A proper drainage of the operation field, and also of the pleural cavity if opened, is helpful and is thus being performed in all our patients with open thoracic surgery. The blood losses from the chest tube were significant in our cases, especially in those where mammary artery was used. We also witnessed the fact how important it was to leave the drainage for sufficiently a long time. Quite substantial losses might be observed even after 24 hours postoperatively. That is also why in our study we were removing the drains and tubes as long as 48 hours after the operations. A sufficiently long period of draining may prevent other postoperative complications, namely the hemopericardium with tamponade, the hemothorax and pneumothorax.

Reduction of blood losses and their appropriate drainage lowers the risk of other postoperative complications. Decrased rate of transfusion lowers the risk of posttransfusion complications, as well as the economic demands of the whole treatment.

\section{Conclusion}

Harvesting and using the mammary artery for revascularization is accompanied by the statistically significant increase of peroperative and postoperative blood losses. These are being caused by an enlargement of wound area on the internal surface of the chest wall when harvesting the artery.

Due to the local application of aprotinin on the wound area after mammary artery harvesting, together with the pericardial sac wash out by aprotinin (in the total amount of $100000 \mathrm{u}$. and $500000 \mathrm{u}$. respectively), we succeeded in decreasing the postoperative drain losses and even the number of blood transfusions, as well.

\section{References}

1. Aarnio P, Kettunen S, Harjula A. Pleural and pulmonary complications after bilateral internal mammary artery grafting. Scand J Thorac Cardiovasc Surg 1991;25:175-8.

2. Angelini GD, Bryan AJ, Dion R. Arterial conduits in myocardial revascularization. Arnold: Oxford Univ. Press, 1996.

3. Bidstrup BP, Harrison J, Royston D et al. Aprotinin therapy in cardiac operations: A report on use in 41 cardiac centers in the United Kingdom. Ann Thorac Surg 1993;55:971-6.

4. Bogers J, Pardijs W, Van Herwerden L, Bos E. Chylothorax as a complication of harvesting the left internal thoracic artery in coronary artery bypass surgery. Cardio-thorac Surg 1993; 7:555-6.

5. Breall J, Kim D, Baim D, Skillman J, Grossman W. Coronary- subclavian steal: An unusual cause of angina pectoris after successful internal mammary-coronary artery bypass grafting. Cathet Cardiovasc Diagn 1991;24:274-6.

6. Chen R, Frazier O, Cooley D. Antifibrinolytic therapy in cardiac surgery. Tex Heart Inst 1995;22:211-5.

7. Fremes SE, Wong BI, Lee $\mathrm{E}$ et al. Metaanalysis of prophylactic drug treatment in the prevention of postoperative bleeding. Ann Thorac Surg 1994;58:1580-8. 
8. Friedel N, Hetzer R, Royston D. Blood use in cardiac surgery. Darmstadt: Steinkopff, New York: Springer, 1991

9. Kesteven PJL. Haemostatic changes during cardiopulmonary bypass. Perfusion 1990;5:9-19.

10. Levy JH. Aspirin and bleeding after coronary artery bypass grafting. Anesth Analg 1994;79:1-3.

11. Manifold DK, Large SR. Sternal wound dehiscence after internal mammary artery harvesting. Eur J Cardio-Thorac Surg 1994;8:46-7.

12. Mills NL. Internal mammary arterial coronary bypass grafts: preparation, strategy and technique. Proceedings of the workshop on arterial conduits for myocardial revascularization. Rome: Galeno editrice Perugia, 1994.

13. O' Regan DJ, Giannopoulos N, Mediratta A et al. Topical aprotinin in cardiac operations. Ann Thorac Surg 1994;58:778-81.

14. Pearson DT. Bleeding following open-heart surgery. Perfusion 1990;5:53-6.

15. Royston D, Taylor KM, Bidstrup BP et al. Effect of aprotinin on need for blood transfusion after repeat open-heart surgery. Lancet 1987;Dec 5:1289-92.

16. Tatar H, Cicek S, Demirkilic U et al. Topical use of aprotinin in open heart operations. Ann Thorac Surg 1993;55:659-61.

17. Vahl C, Carl I, Muller-Vahl H, Struck E. Brachial plexus injury after cardiac surgery. J Thorac Surg 1991;102:724-9.

18. Woodman RC, Harker LA. Bleeding complications associated with cardiopulmonary bypass. Blood 1990;76:1680-97.

Submitted September 1999

Accepted September 1999.

MUDr. Jiří Mandák, Ph.D.,

Charles University in Prague, Faculty of Medicine in Hradec Králové,

Department of Cardiosurgery, 50005 Hradec Králové, Czech Republic. e-mail: jiri.mandak@usa.net 